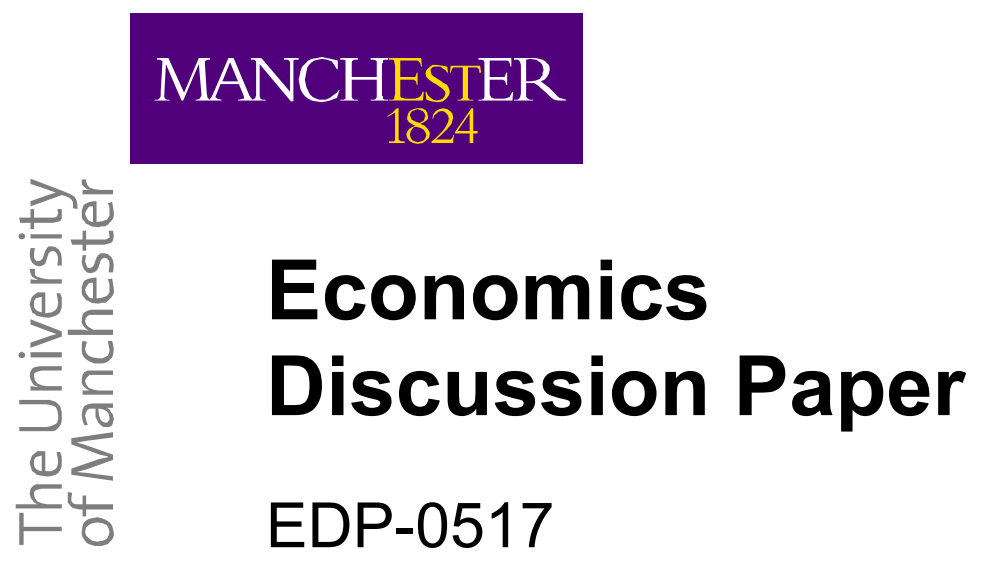

Tax competition, location, and horizontal foreign direct investment

by

Kristian Behrensy and Pierre M. Picard

September 2005

pierre.picard@manchester.ac.uk

School of Social Sciences,

The University of Manchester

Oxford Road

Manchester M13 9PL

United Kingdom 


\title{
Tax competition, location, and horizontal foreign direct investment*
}

\author{
Kristian Behrens $^{\dagger} \quad$ Pierre M. Picard ${ }^{\ddagger}$ \\ September 20, 2005
}

\begin{abstract}
We develop a model of capital tax competition in which imperfectly competitive firms choose both the number of plants they operate and their location. When compared to models with single-plant firms, the presence of multinationals reverses some standard results. First, instead of being subsidized, capital may actually be taxed in equilibrium, which shows that the presence of taxable 'multinational rents' relaxes tax competition. Second, even when firms are subsidized, their subsidy-inclusive profits may be decreasing in subsidies, due to fiercer price competition by more multinationals. Third, multinationals may give rise to multiple equilibria in the tax game, one of which can be a 'subsidy trap' characterized by many multinationals, high subsidy levels, and low welfare.
\end{abstract}

Keywords: capital tax competition; international trade; multi-plant location problem; foreign direct investment; imperfect competition

JEL Classification: F12; F23; H27; H73; R12

*We thank Jon Hamilton and David Wildasin for useful comments and suggestions. The usual disclaimer applies.

†CORE, Université catholique de Louvain, 34 voie du Roman Pays, 1348 Louvain-laNeuve, Belgium. Office: +3210474305. E-mail: behrens@core.ucl.ac. be

${ }^{\ddagger}$ CORE, Université catholique de Louvain, Belgium; and University of Manchester, UK. E-mail: pierre.picard@manchester.ac.uk, picard@core.ucl.ac.be 


\section{Introduction}

It is a widely documented fact that tax incentives are a pervasive instrument used by governments and developers to attract mobile capital and foreign direct investment (henceforth, FDI; see UNCTAD, 2000, for a recent survey). Although market access, trade costs, and strategic considerations surely explain the larger part of firms' decisions to adopt a multinational structure, it has been recognized that taxes and tax incentives matter a lot in influencing the subsequent destinations and levels of FDI flows (see, e.g., Cummins and Hubbard, 1995; Devereux and Freeman, 1995). Given the empirical importance of financial and fiscal incentive packages, it is natural to ask whether government competition creates windfall gains for mobile firms, thus leading to inefficient outcomes by putting strain on governments' budgets. In recent years, such fears have been increasingly voiced by politics and the public, given the apparent inflation of subsidies granted to firms and investors. Many incentive packages are indeed perceived as being 'overly generous', with total state contribution matching up to $30 \%$ of company investments. ${ }^{1}$ This may be regarded as yet another illustration of the well-known 'race to the bottom', where tax rates are set to inefficiently low levels or where capital is subsidized at inefficiently high rates.

Although the tax competition literature has extensively analyzed the role of FDI, it has often overlooked the multinational firms' objective to gain access to spatially separated market (see, e.g., Oates 1972; Wilson 1986; Wildasin 1988). Recently, several contributions have linked more closely tax competition, international trade, and spatial issues in models of imperfect competition. Building on the 'new economic geography' paradigm, several authors have investigated tax issues when firms and workers are allowed to agglomerate in some locale in response to economic opportunities (e.g., Ludema and Wooton, 2000; Baldwin and Krugman, 2004; Ottaviano and van Ypersele, 2005; Borck and Pflüger, 2005). Yet, such contributions still fail to fully capture the impact of horizontal FDI and firms' location choices on tax competition outcomes, because firms are not allowed to alter their production structures and duplicate plants to overcome trade barriers. ${ }^{2}$

\footnotetext{
${ }^{1}$ For example, total state financial inventives for the Smart automobile plant of Mercedes-Benz and Swatch in Hambach, France, amounted to US\$111 million, for a total company investment of US $\$ 370$ million (Raff, 2004, p.2747). See also Görg and Greenaway (2002) for other illustrative examples.

${ }^{2}$ Baldwin and Krugman (2004), Haufler and Pflüger (2004), and Borck and Pflüger
} 
Given the growing importance of multinationals it is, in our opinion, important to develop a framework in which the relationship between production structure, location, and tax competition can be more fully analyzed. Doing so may especially allow us to better understand why the empirical literature finds only somewhat mixed evidence about the importance of international tax competition. Indeed, it is known that, although average statutory taxes have fallen in OECD countries during the 1980s and 90s, tax bases have increased at the same time so that effective marginal tax rates and tax revenues have remained rather stable (Devereux, Griffith and Klemm, 2002). Stated differently, the empirical facts hardly support the thesis of a strong 'race to the bottom'. Also, whereas many empirical contributions support the view that capital is mobile between alternative foreign locations, they generally find no significant capital mobility between domestic and foreign locations (e.g., Devereux and Freeman, 1995). The explanation we propose in this paper is that firms need not relocate capital from the domestic to the foreign country in response to tax changes, but that they may rather raise capital to establish additional plants in foreign locations, thereby de facto reducing capital mobility. More precisely, we show that tax competition can be drastically weakened when firms have the option to establish an additional plant rather than simply relocating their unique existing one.

To illustrate this point concisely, we develop a two-country model of capital tax competition in which mobile firms endogenously choose both their location and production structure. All firms sell their products in both countries and face trade costs, so that they choose to operate a single plant in one of the two countries when transport costs or trade barriers are small, whereas they build a second plant and incur additional fixed costs in the opposite case. As in Ottaviano and van Ypersele (2005), utilitarian governments offer subsidies (or tax credits) to attract firms and to increase their

(2005) develop 'new economic geography' models of capital tax competition with product differentiation, trade costs, and imperfect competition. Contrary to us, they do not allow for multinational firms and their framework abstracts from pro-competitive effects. Ottaviano and van Ypersele (2005) develop a model similar to ours featuring pro-competitive effects. Yet, they do not allow for multinationals by assuming that firms operate in a single country only. Most other contributions deal with multinationals by focussing on the location and investment choices of a single monopolist (see, e.g., Haufler and Wooton, 1999, 2005; Devereux and Hubbard, 2003; Raff 2004). The 'new economic geography' literature dealing with multinationals usually disregards the issue of tax competition and the impacts this may have on firms' choices (e.g., Markusen and Venables, 1998, 2000; Navaretti and Venables, 2004). 
residents' consumption surplus and profit claims. Whereas single-plant firms generally constitute a highly mobile tax base, multinational firms represent a more immobile one. The reason is that being multinational may give rise to taxable rents (via trade cost savings), so that marginal changes in subsidies do not alter firms' location choices. By consequence, when many firms engage in horizontal FDI the tax bases are relatively less elastic and subsidy competition is likely to fall. There would, for example, be no scope for tax competition in a world where all firms are 'McDonald-type' multinational corporations which need to build and operate an outlet in each locale to sell their 'hamburgers' there.

Previewing our main results, we show that the outcome of the tax competition game crucially depends on the level of trade costs and the cost of capital before subsidies. If, on the one hand, trade costs are low relative to the cost of capital, firms will always choose to serve both markets from a single production site. In that case, the tax base is fully mobile and firms react in the usual way to differences in taxes by changing locations: tax rates are strategic complements and capital will always be subsidized in any noncooperative tax equilibrium (see, e.g., Wilson, 1999; Haufler and Wooton, 1999; Ottaviano and van Ypersele, 2005). If, on the other hand, trade costs are high relative to the cost of capital, firms will always choose to run multiple production plants and serve each market locally through subsidiary sales. In that case, multinationals are more profitable than single-plant exporters so that governments may actually tax away firms 'organizational rents'. This in turn destroys the incentives for harmful tax competition and lowers subsidies to capital since the tax base is immobile. ${ }^{3}$ Finally, when trade costs take intermediate values relative to the cost of capital, both multinationals and single-plant firms coexist in equilibrium. In that case, the tax base is partially immobile and capital may be either taxed or subsidized, depending on firms' profitability before subsidies.

Our analysis further reveals that not only the difference in tax rates between countries matters in the presence of multinationals, but also their

\footnotetext{
${ }^{3}$ Note that this result is similar to the one obtained in models with asymmetric country sizes, in which the larger country displays a 'home market effect' and may usually tax away 'agglomeration rents' (e.g., Haufler and Wooton, 1999; Baldwin and Krugman, 2004; Ottaviano and van Ypersele, 2005). It also suggests that tax competition in non-traded goods industries (e.g., some consumer services which require firms to have 'nexus' in many locales) may be different than in traded goods industries, since firms must operate in the different markets which makes them less mobile and, therefore, easier to tax.
} 
absolute level across countries. Indeed, an increase in the average level of subsidies decreases the cost of capital and leads to the entry of multinational firms, which makes the global economy more competitive by reducing markups. As we will show, this has important implications for the nature of tax competition by creating complementarities in firms' locational and organizational choices. ${ }^{4}$ Roughly speaking, by 'going multinational' firms make the global economy more competitive, thereby cutting profits of single-plant exporters by making their access to foreign markets more difficult. This in turn entices exporters to also 'go multinational', thereby further increasing competition. A by-product of this complementarity is that there may be multiple equilibria in the tax game, one of which can a 'subsidy trap' characterized by many multinationals, high subsidies, and low welfare.

The remainder of the paper is organized as follows. In Section 2, we present the model and derive the equilibrium for given tax rates and a given spatial structure. Section 3 then discusses the spatial allocation and the production structure of firms taking tax rates as given. In Section 4, we describe governments' tax choices when they play a non-cooperative tax game, and we fully characterize the equilibria as a function of the before-tax cost of capital. Section 5 discusses the robustness of our main results and presents some comparative statics. Section 6 finally concludes.

\section{The model}

Our framework builds on Ottaviano and van Ypersele (2005), who introduce capital tax competition in the 'new economic geography' model by Ottaviano and Thisse (2004).

\subsection{Preferences}

Consider an economy with two countries, labeled $H$ and $F$. Variables associated with each country will be subscripted accordingly. There is a total mass of $L$ immobile consumers in the economy, and each country is endowed with a mass $L / 2$ of them. All consumers have identical quasi-linear preferences over a homogeneous good and a continuum of $N$ varieties of a horizontally

\footnotetext{
${ }^{4}$ This feature of multinational activity goes unnoticed in both the numerous models focussing on the choices of a single monopolist, as well as the models relying on CES preferences and constant mark-ups.
} 
differentiated good. The subutility over the varieties $v \in[0, N]$ of the differentiated good is quadratic as in Ottaviano et al. (2002). The utility of a representative consumer in country $i=H, F$ is given by:

$$
U_{i}=\alpha \int_{0}^{N} q_{i}(v) \mathrm{d} v-\frac{\beta-\gamma}{2} \int_{0}^{N}\left[q_{i}(v)\right]^{2} \mathrm{~d} v-\frac{\gamma}{2}\left[\int_{0}^{N} q_{i}(v) \mathrm{d} v\right]^{2}+q_{i}^{o},
$$

where $q_{i}(v)$ denotes the consumption of the differentiated variety $v, q_{i}^{o}$ stands for the consumption of the homogeneous good, and $\alpha>0, \beta>\gamma>0$ are utility parameters.

All consumers are endowed with one unit of labor, one unit of capital and $\bar{q}_{o}>0$ units of the homogeneous good. Labor and capital are supplied inelastically. The homogeneous good is produced under perfect competition using one unit of labor only, and we assume that it can be costlessly traded between countries. In what follows, we choose it as the numéraire, i.e., $p_{i}^{o}=p^{o}=1$. Each consumer maximizes her utility (1) subject to the budget constraint

$$
\int_{0}^{N} p_{i}(v) q_{i}(v) \mathrm{d} v+q_{i}^{o} \leq r_{i}+w_{i}+\bar{q}_{o}
$$

where $p_{i}(v)$ is the consumer price of variety $v, r_{i}$ is the rental rate of capital, and $w_{i}$ is the wage in country $i$.

In what follows, we assume that all varieties produced in the same country can be treated symmetrically. This allows us to alleviate notation by dropping the variety index $v$. Let $p_{i j}$ stand for the price of a variety produced in country $i$ when sold in country $j$, and denote by $N_{i}$ the mass of varieties produced in country $i$. Maximizing (1) subject to (2) yields the following demands for varieties produced in country $i$ and consumed in country $j$ :

$$
q_{i j}=a-(b+c N) p_{i j}+c P_{j}
$$

where $a, b$ and $c$ are positive coefficients given by

$$
a \equiv \frac{\alpha}{\beta+(N-1) \gamma} \quad b \equiv \frac{1}{\beta+(N-1) \gamma} \quad c \equiv \frac{\gamma}{(\beta-\gamma)[\beta+(N-1) \gamma]}
$$

and where

$$
P_{j} \equiv N_{j} p_{j j}+N_{i} p_{i j} \quad i \neq j
$$

can be interpreted as the manufacturing price index ( $N$ times the average price) in the country $j$ of consumption. 


\subsection{Technology}

We assume that each firm owns some firm-specific asset (e.g., a patent right) which grants it some monopoly power over a single variety. The total mass of varieties $N=N_{H}+N_{F}$ therefore also stands for the total mass of firms in the global economy. Contrary to the monopolistic competition literature, we assume that $N$ is fixed so that there may be pure profits in the economy. This is either because entrepreneurs are scare, or because the number of patents is limited, or because there exist significant barriers to entry in the industry. Thus, our analysis may be seen as being short-run since it does not account for entry in, or exit from, the industry.

We assume that firms do not only choose their location, but that they also choose the number of plants they operate, i.e., they make both an organizational and a locational choice. Firms can choose to be either single- or double-plant (which we, henceforth, simply refer to as 'multi-plant'). In the former case, firms run a single production unit and serve the foreign market through exports, whereas in the latter case they operate two production units and serve each market locally. We denote by $n_{i}$ and $m$ the mass of single- and multi-plant firms based in country $i=H, F$ respectively. ${ }^{5}$ The total mass of varieties and, therefore, of firms is given by

$$
N=n_{H}+n_{F}+m \text {. }
$$

Capital is assumed to be perfectly mobile across sectors and countries, whereas labor is perfectly mobile across sectors but immobile internationally. All firms have access to the same technology and produce their variety by using both labor and capital. Following Ottaviano and Thisse (2004), we assume that labor enters only the variable cost, whereas the fixed cost is incurred in terms of capital only. Without loss of generality, we may set the marginal labor requirement to zero since this amounts to rescaling firms' demand intercepts (see Ottaviano et al., 2002). Firms require $\phi$ units of capital to set up a plant in any country. We assume that the rental rate $r$ of capital is exogenously fixed. Constant rental rates may reflect the constant degree of intertemporal substitution of lenders, or simply the fact that the

\footnotetext{
${ }^{5}$ We do not need to keep track of where multi-plant firms are headquartered. This is because we assume that fixed costs are the same in both countries. When fixed costs differ, headquarters will be exclusively located in the low fixed cost country (see, e.g., Navaretti and Venables, 2004, p.54).
} 
industry is small when compared to the rest of the economy. Hence, when governments do not subsidize capital, the cost of a plant is equal to $\phi r$.

When governments $H$ and $F$ do subsidize capital at the rates $\xi_{H}$ and $\xi_{F}$, the costs of a plant are equal to $\phi r\left(1-\xi_{H}\right)$ and $\phi r\left(1-\xi_{F}\right)$, respectively. For the sake of exposition, we denote the firms' after-subsidy fixed costs by $\phi r-s_{H}$ and $\phi r-s_{F}$, where $s_{H}=\phi r \xi_{H}$ and $s_{F}=\phi r \xi_{F}$ stand for the values of subsidies. Since $r$ and $\phi$ are assumed to be constant, the subsidies $s_{H}$ and $s_{F}$ are lump sum transfers to the firms which depend on the number and location of their investments. Note that all firms in a country are equally subsidized. ${ }^{6}$ Thus, subsidies may be seen as playing the dual role of trying to attract new firms and preventing existing firms from leaving. ${ }^{7}$ Note, finally, that nothing precludes subsidies a priori from being negative, in which case they are equivalent to source-based capital taxes payed in the location where the capital is used. ${ }^{8}$

Shipping each variety of the manufactured good across countries is costly, whereas shipping it within each country is free. More specifically, shipping one unit of any variety between the two countries entails a per-unit cost of $\tau>0$ units of the numéraire. Note that the existence of transport costs ensures that multi-plant firms behave like local firms in each domestic market and serve the market through subsidiary sales only. Indeed, given plant-level scale economies and transport costs the firm will never produce a fraction of demand locally while importing the rest from abroad. Hence, our model is of the 'proximity-vs-scale' type (Barba Navaretti and Venables, 2004).

Firms play the following two-stage game: (i) they choose the number and

\footnotetext{
${ }^{6}$ Equal treatment of firms circumvents the problem of "harmful measures", which are considered to arise if tax incentives apply only to non-residents, i.e., if they are discriminatory in nature (UNCTAD, 2000). Recently, "the EU adopted a Code of Conduct for business taxation, in which member states committed themselves to refrain from 'unfair' tax policies that discriminate against (less mobile) domestic firms in favour of (more mobile) multinational firms (Haufler and Wooton, 2005, p.2).

${ }^{7}$ Tax incentives can be broadly defined as including "measures specifically designed either to increase the rate of return of a particular FDI undertaking, or to reduce (or retribute) its costs or risks" (UNCTAD, 2000, p.11). They include, among others, reduced tax rates on profits, tax holidays, accelerated depreciation, and loss carry forwards.

${ }^{8}$ In this paper, we do not consider residence-based taxes. Under perfect information, residence-based taxes are non-distortionary lump sum transfers which do not generate tax competition between governments. The main discussion about residence-based taxes arises under imperfect information when tax authorities can hardly observe and collect the foreign capital incomes of their residents. This discussion is beyond the scope of the present paper.
} 
location of their production plants; and (ii) given their previous choices, they set profit maximizing prices.

We first derive the price equilibrium of the second stage in the following sub-section, and then present the equilibrium in firms' location and structure in Section 3.

\subsection{Price equilibrium}

Assume that both the organizational and spatial structure $n_{H}, n_{F}$ and $m$ of the industry are given. In our framework featuring a continuum of firms, each firm is negligible to the market and sets its own prices taking all other variables (including the subsidies) as given. In accord with empirical evidence (see, e.g., Head and Mayer, 2000; Haskel and Wolf, 2001), we assume that international markets are segmented. Firms are hence free to set prices specific to each national market they sell their product in.

In what follows, we superscript variables pertaining to single-plant firms by $s$ and to multi-plant firms by $m$. To shorten the exposition, we derive all expressions for country- $H$ firms only.

We solve the game by backward induction starting with the price equilibrium for any given distribution of firms. The profit before subsidy of a single-plant firm established in country $H$ is given by

$$
\Pi_{H}^{s}=\frac{L}{2} p_{H H} q_{H H}+\frac{L}{2}\left(p_{H F}-\tau\right) q_{H F}-\phi r,
$$

whereas the profit before subsidy of a multi-plant firms is given by

$$
\Pi^{m}=\frac{L}{2} p_{H H} q_{H H}+\frac{L}{2} p_{F F} q_{F F}-2 \phi r .
$$

Since multi-plant firms serve each market locally only, their pricing decisions are identical to those of the single-plant firms operating in the same market. Maximizing profits (6) and (7) with respect to $p_{H H}$ and $p_{H F}$, substituting the price aggregate (4) and solving for the equilibrium prices and quantities yields:

$$
\begin{gathered}
p_{H H}^{*}=\frac{2 a+c n_{F} \tau}{2(2 b+c N)} \quad p_{F H}^{*}=p_{H H}^{*}+\frac{\tau}{2} \\
q_{H H}^{*}=(b+c N) p_{H H}^{*} \quad q_{F H}^{*}=(b+c N)\left(p_{F H}^{*}-\tau\right),
\end{gathered}
$$


with symmetric expressions for country- $F$ firms. Using $N=n_{H}+n_{F}+m$, the equilibrium price can be expressed as follows:

$$
p_{H H}^{*}=\frac{2 a+c N \tau-c\left(m+n_{H}\right) \tau}{2(2 b+c N)}=\frac{2 a+c n_{F} \tau}{2(2 b+c N)} .
$$

This shows that prices in country $H$ decrease with the mass of plants located in that country. Note that the mass of multinational firms appears in both countries' equilibrium prices. Hence, contrary to single-plant firms which have only an impact on prices in the country they are located in, multinational firms put downward pressure on prices in both countries.

To simplify the analysis, we assume that trade costs are sufficiently low such that international trade is always feasible. It is readily verified that $q_{H F}^{*}>0$ and $q_{F H}^{*}>0$ for all allocations $\left(n_{H}, n_{F}, m\right)$ provided that

$$
\tau<\tau^{\text {trade }} \equiv \frac{2 a}{2 b+c N}
$$

Condition (10), which is henceforth referred to as trade feasibility condition, also makes sure that international prices net of transport costs always remain strictly positive. When (10) holds, international trade occurs regardless of firms' choices during the first stage of the game.

Using the profit-maximizing prices (8) and quantities (9), the profits can be expressed as follows:

$$
\begin{aligned}
\Pi_{H}^{s}\left(p_{H H}, p_{F F}\right) & =\frac{L(b+c N)}{2}\left[p_{H H}^{2}+\left(p_{F F}-\frac{\tau}{2}\right)^{2}\right]-\phi r \\
\Pi^{m}\left(p_{H H}, p_{F F}\right) & =\frac{L(b+c N)}{2}\left[p_{H H}^{2}+p_{F F}^{2}\right]-2 \phi r .
\end{aligned}
$$

The consumer surplus of a resident in country $H$ is given by

$$
\begin{aligned}
S_{H}\left(p_{H H}, n_{H}, n_{F}, m\right)= & \frac{a^{2} N}{2 b}-a\left[\left(n_{H}+m\right) p_{H H}+n_{F} p_{F H}\right] \\
& +\frac{b+c N}{2}\left[\left(n_{H}+m\right) p_{H H}^{2}+n_{F} p_{F H}^{2}\right] \\
& -\frac{c}{2}\left[\left(n_{H}+m\right) p_{H H}+n_{F} p_{F H}\right]^{2} .
\end{aligned}
$$

We now turn to the issue of subsidy competition between governments when firms are geographically mobile and can decide on the number of production plants they operate in the global economy. 


\section{Firms' structure and location}

Subsidies affect both the location and production organization of firms. We therefore begin by investigating which equilibrium configurations $\left(n_{H}^{*}, n_{F}^{*}, m^{*}\right)$ may arise for any given couple of subsidies $\left(s_{H}, s_{F}\right)$. We have to distinguish between the following cases.

(i) Pure single-plant configurations (i.e., $m^{*}=0$ ) imply that subsidyinclusive profits of single-plant firms are equalized across countries: $\Pi_{H}^{s}+$ $s_{H}=\Pi_{F}^{s}+s_{F}$. Evaluating (11) and (12) at the equilibrium prices (8), the profit differential between single-plant firms in countries $H$ and $F$ is equal to

$\Pi_{H}^{s}+s_{H}-\left(\Pi_{F}^{s}+s_{F}\right)=K\left(n_{F}-n_{H}\right)+s_{H}-s_{F}, \quad K \equiv \frac{L c \tau^{2}(b+c N)}{4(2 b+c N)}>0$.

Equating this profit differential to zero, the equilibrium masses of firms in countries $H$ and $F$ are given by

$$
n_{H}^{*}=\frac{N}{2}+\frac{1}{2 K}\left(s_{H}-s_{F}\right) \quad \text { and } \quad n_{F}^{*}=\frac{N}{2}-\frac{1}{2 K}\left(s_{H}-s_{F}\right) .
$$

Hence, by making capital cheaper, a country's subsidy attracts single-plant firms from the other country. In a pure single-plant configuration, subsidy competition is of a 'win-loose' type in terms of number of local firms and, therefore, in term of access to products.

Feasibility of a pure single-plant configuration further requires that singleplant firms are more profitable than multi-plant firms:

$$
\begin{aligned}
\Pi^{m}+s_{j}-\Pi_{i}^{s} \leq 0, i=H, F & \Longleftrightarrow s_{H}+s_{F} \leq 2 B-N K \\
n_{H}^{*} \geq 0 & \Longleftrightarrow s_{F} \leq s_{H}+N K \\
n_{F}^{*} \geq 0 & \Longleftrightarrow s_{F} \geq s_{H}-N K,
\end{aligned}
$$

where

$$
B \equiv \phi r-\frac{(b+c N)[4 a-(2 b+c N) \tau]}{8(2 b+c N)} L \tau .
$$

The set of subsidies supporting this configuration, delimited by (15)-(17), is depicted by zone (i) in Figure 1.

Insert Figure 1 about here. 
(ii) Mixed configurations, where single- and multi-plant firms may coexist (i.e., $m^{*}>0, n_{H}^{*} \geq 0$ and $n_{F}^{*} \geq 0$ ), require that subsidy-inclusive profits of all types of firms are equalized across countries: $\Pi_{H}^{s}+s_{H}=\Pi_{F}^{s}+s_{F}=$ $\Pi^{m}+s_{H}+s_{F}$. The profit differential between a multi- and a single-plant firm in country $H$ can be expressed as follows:

$$
\Pi^{m}-\Pi_{H}^{s}=\frac{L}{2}(b+c N) \tau\left(p_{F F}^{*}-\frac{\tau}{4}\right)-\phi r+s_{F},
$$

a symmetric expression holding for country $F$. Equating the above profit differentials to zero, we readily obtain the following equilibrium masses of plants in countries $H$ and $F$ :

$$
n_{H}^{*}+m^{*}=\frac{N K-2 B+s_{H}}{K} \quad \text { and } \quad n_{F}^{*}+m^{*}=\frac{N K-2 B+s_{F}}{K} .
$$

By making capital cheaper, a country's subsidy increases the number of plants in its market. Using $N=n_{H}+n_{F}+m$, we get the equivalent conditions

$$
n_{H}^{*}=\frac{B-s_{F}}{K}, \quad n_{F}^{*}=\frac{B-s_{H}}{K}, \quad m^{*}=\frac{N K-2 B+s_{H}+s_{F}}{K} .
$$

It is important to observe that the mass of single-plant firms in country $H$ is independent of the subsidy $s_{H}$ set by this country. This subsidy only induces single-plant firms in country $F$ to build a second plant in country $H$.

Finally, feasibility of the configuration requires that

$$
\begin{aligned}
& n_{H}^{*} \geq 0 \Longleftrightarrow s_{F} \leq B \\
& n_{F}^{*} \geq 0 \Longleftrightarrow s_{H} \leq B \\
& m^{*}>0 \Longleftrightarrow s_{H}+s_{F}>2 B-N K .
\end{aligned}
$$

The set of subsidies supporting this configuration, delimited by (19)-(21), is depicted by zone (ii) in Figure 1.

(iii) Pure multi-plant configurations (i.e., $m^{*}=N$ and $n_{H}^{*}=n_{F}^{*}=$ $0)$ are supported for subsidies such that $\Pi^{m}+s_{H}+s_{F}>\Pi_{H}^{s}+s_{H}$ and $\Pi^{m}+s_{H}+s_{F}>\Pi_{F}^{s}+s_{F}$, i.e., for $s_{F}>B$ and $s_{H}>B$. Under these conditions, no firm has an incentive to shut-down a plant given the current level of subsidies. The set of subsidies supporting this configuration is depicted in by zone (iii) in Figure 1. 
(iv) Mixed configurations with agglomeration in $H$ (i.e., $n_{F}^{*}=0$, $n_{H}^{*}>0$, and $m^{*}>0$ ) require that subsidy-inclusive profits of single-plant firms in $H$ and multi-plant firms are equalized: $\Pi_{H}^{s}+s_{H}=\Pi^{m}+s_{H}+s_{F}$. This yields

$$
n_{H}^{*}=\frac{B-s_{F}}{K} \quad \text { and } \quad m^{*}=N-n_{H}^{*} .
$$

Feasibility of this configuration further requires that $n_{H}^{*} \geq 0, m^{*} \geq 0$ and $\Pi_{H}^{s}+s_{H}>\Pi_{F}^{s}+s_{F}$, which implies that $B-N K \leq s_{F} \leq B$ and $s_{H}>B$. The set of subsidies supporting this configuration is depicted by zone (iv) in Figure 1.

(v) Full agglomeration in $H$ (i.e., $n_{H}^{*}=N, n_{F}^{*}=m^{*}=0$ ) is feasible when $\Pi_{H}^{s}+s_{H}>\Pi_{F}^{s}+s_{F}$ and $\Pi_{H}^{s}>\Pi^{m}+s_{F}$, which implies that $s_{F}<s_{H}-K N$ and $s_{F}<B+K N$. The set of subsidies supporting this configuration is depicted by zone (v) in Figure 1.

Note, finally, that there exist by symmetry two additional configurations $\left(\mathrm{iv}^{\prime}\right)$ and $\left(\mathrm{v}^{\prime}\right)$ that are the mirror cases of (iv) and (v), namely mixed configurations with single-plants in $F$ only, and full agglomeration in $F$. For the sake of brevity, we do not present these configurations formally (see Figure 1).

Because subsidies affect both firms' structure and location, their impact on subsidy-inclusive profits is a priori ambiguous. A more careful analysis of this point will prove useful in guiding intuition as to which additional effects may arise in the presence of multinationals. Let us focus on configurations (i) and (ii) only. Indeed, as will become clear in the next section, those configurations are the relevant ones for subsidy competition. In the pure single-plant configuration (i), a subsidy increase directly raises the profit of firms located in that country and, by triggering relocation towards it, also raises profits in the other country by making competition there less fierce. Indeed, it is easy to show that in (the interior of the domain of) configuration (i), we have

$$
\frac{d\left(\Pi_{H}^{s}+s_{H}\right)}{d s_{H}}=\frac{b+n_{H}^{*} c}{2 b+c N}>0 \quad \text { and } \quad \frac{d\left(\Pi_{H}^{s}+s_{H}\right)}{d s_{F}}=\frac{b+n_{F}^{*} c}{2 b+c N}>0 .
$$

Yet, this result does not hold in the presence of multi-plant firms since subsidies affect the number of plants rather than firms' location. The result being that a subsidy increases competition in the country where new plants are built, whereas it leaves competition in the other country unchanged. 
Thus, competition in the global economy increases and profits fall in both countries. We can indeed show that in configuration (ii) we have

$$
\frac{d\left(\Pi_{H}^{s}+s_{H}\right)}{d s_{H}}=\left(1-\frac{2 p_{H H}^{*}}{\tau}\right)<0 \quad \text { and } \quad \frac{d\left(\Pi_{H}^{s}+s_{H}\right)}{d s_{F}}=\left(1-\frac{2 p_{F F}^{*}}{\tau}\right)<0
$$

since $p_{H H}^{*}>\tau / 2$ and $p_{F F}^{*}>\tau / 2$ under the trade feasibility condition (10). Hence, the impact of subsidies on profits is drastically modified in the presence of multi-plant firms, due to the possibility of firms' endogenously changing their production structure.

Proposition 1 (firms' profits) Suppose that governments increase their subsidies or reduce their taxes. In pure single-plant configurations (i), profits after subsidy increase; whereas in mixed configurations (ii), profits after subsidy decrease as more and more firms choose to adopt a multi-plant structure.

It is easy to show that profits are minimized in two cases. Firstly, when firms are heavily taxed (i.e., $\left(s_{H}, s_{F}\right) \rightarrow(-\infty,-\infty)$ in a pure single-plant configuration, which yields negative profits below some threshold); and secondly, when firms are highly subsidized in the mixed configurations (i.e., $\left(s_{H}, s_{F}\right)=(B, B)$, which yields a local minimum for profits). In what follows, we restrict our attention to the meaningful situation in which firms' subsidy-inclusive profits are positive so that production takes place. This imposes, firstly, that taxes are not too high so that firms make positive profits in configuration (i); and, secondly, that profits are positive at the point $\left(s_{H}, s_{F}\right)=(B, B)$, which implies that firms' profits are always positive for any optimal subsidies in configuration (ii). Because $\Pi^{m}+s_{H}+s_{F}=\Pi^{m}+2 B$ when $s_{H}=s_{F}=B$, the formal condition for this is that

$$
\frac{1}{4} L(b+c N)\left(\tau^{\text {trade }}-\tau\right)^{2}>0
$$

which is always satisfied since $\tau<\tau^{\text {trade }}$.

To sum up, our analysis shows that subsidies have a strong impact on firms' location, structure, and profits. In particular, when subsidies are small relative to fixed costs, the industry includes single-plant firms only, whereas it also includes multinationals when they are larger. In the absence of multinational firms, the location of production is quite sensitive to the difference in subsidies. By contrast, in the presence of multinational firms, the location 
of production is not sensitive to the amount of subsidy granted to firms, so that the subsidy differential plays a lesser role. Finally, firms may gain or lose from higher subsidies, depending on their organizational structure. In particular, profits may well decrease with larger subsidies as the global economy becomes more competitive due to an increasing mass of multinationals. We now explore the impact of multinational firms on governments' subsidy competition.

\section{Subsidy competition}

Ottaviano and van Ypersele (2005) have shown that tax competition leads to subsidies to capital funded by taxes on labor. Stated differently, governments subsidize capital to attract mobile firms to their country. What happens when firms can not only choose location but also their number of plants? How does this affect the insights gained from tax competition models?

In this section, we assume that firms and capital are wholly owned by residents of countries $H$ and $F$ ('fully diversified portfolio' assumption). ${ }^{9}$ More precisely, country $H$ 's residents get one-half of firms' profits after subsidy and one-half of the capital rents. Country $F$ 's residents get the same shares of profits and capital rentals.

The government of country $H$ chooses $s_{H}$ to maximize its residents' welfare given by

$$
\begin{aligned}
W_{H}= & \frac{L}{2} S_{H}+\frac{1}{2}\left[n_{H}\left(\Pi_{H}^{s}+s_{H}+\phi r\right)+n_{F}\left(\Pi_{F}^{s}+s_{F}+\phi r\right)\right. \\
& \left.+m\left(\Pi^{m}+s_{H}+s_{F}+2 \phi r\right)\right]-\left(n_{H}+m\right) s_{H},
\end{aligned}
$$

which consists of local consumer surplus, one-half of world profits as given by (11)-(12) and including subsidies and capital rents, less the direct cost of subsidizing capital. Differentiating $W_{H}$ with respect to $s_{H}$, we can express

\footnotetext{
${ }^{9}$ Ottaviano and van Ypersele (2005) use a similar assumption. Still, Raff (2004) has shown that the ownership structure of firms and the distribution of profits is not innocuous. In Section 5, we will discuss the robustness of our results under alternative assumptions on the distribution of profit and capital rents.
} 
the impact of a marginal increase in subsidy on local welfare as follows:

$$
\begin{aligned}
\frac{d W_{H}}{d s_{H}} & =\frac{1}{2} \frac{\partial n_{H}}{\partial s_{H}}\left(L \frac{\partial S_{H}}{\partial n_{H}}+\Pi_{H}^{s}+\phi r-s_{H}\right)+\frac{1}{2} \frac{\partial n_{F}}{\partial s_{H}}\left(L \frac{\partial S_{H}}{\partial n_{F}}+\Pi_{F}^{s}+\phi r+s_{F}\right) \\
& +\frac{1}{2} \frac{\partial m}{\partial s_{H}}\left(L \frac{\partial S_{H}}{\partial m}+\Pi^{m}+2 \phi r-s_{H}+s_{F}\right) \\
& +\frac{1}{2} \frac{\partial p_{H H}}{\partial n_{F}} \frac{\partial n_{F}}{\partial s_{H}}\left(L \frac{\partial S_{H}}{\partial p_{H H}}+n_{H} \frac{\partial \Pi_{H}^{s}}{\partial p_{H H}}+n_{F} \frac{\partial \Pi_{F}^{s}}{\partial p_{H H}}+m \frac{\partial \Pi^{m}}{\partial p_{H H}}\right) \\
& +\frac{1}{2} \frac{\partial p_{F F}}{\partial n_{H}} \frac{\partial n_{H}}{\partial s_{H}}\left(n_{H} \frac{\partial \Pi_{H}^{s}}{\partial p_{F F}}+n_{F} \frac{\partial \Pi_{F}^{s}}{\partial p_{F F}}+m \frac{\partial \Pi^{m}}{\partial p_{F F}}\right)-\frac{1}{2}\left(n_{H}+m\right) .
\end{aligned}
$$

In this expression, the last term captures the direct cost of a subsidy paid to all firms. The first three terms represent the indirect effects of the subsidy through relocation of firms at constant prices; whereas the intermediate terms finally indicate the indirect effect of a subsidy through price changes.

\subsection{Optimal subsidies}

We now determine the subsidies government $H$ may potentially choose in the subsidy game for a given value of $s_{F}$. This allows us then to derive and discuss governments' best responses associated with different spatial structures. All standard calculations are relegated to Appendix 1.

To begin with, it is of interest to note that government $H$ will never choose a subsidy $s_{H}$ such that the couple $\left(s_{H}, s_{F}\right)$ lies in the interior of configurations (iii), (iv), (v), (iv $\left.{ }^{\prime}\right)$ or $\left(\mathrm{v}^{\prime}\right)$. Assume, indeed, that the subsidy $s_{H}$ is sufficiently large so that country $F$ has no single-plant firms, which corresponds to either configuration (iii), (iv) or (v). Then every firm operates a plant in country $H$ and possibly one in country $F$. If government $H$ increases its subsidy, this does not alter the distribution of single-plant firms across the two countries. Furthermore, because the subsidy $s_{H}$ has no impact on the decision of building a plant in country $F$, this action does not alter firms' organizational structure. Hence, the only effect of such a subsidy is to raise firms' profits, which cannot be welfare improving since some profits accrue to foreign shareholders. ${ }^{10}$ Formally, one can check in configurations (iii), (iv)

\footnotetext{
${ }^{10}$ As shown in Section 5, this result holds for all possible ways of distributing profits between domestic and foreign shareholders and, therefore, does not depend on our assumption of an equal redistribution.
} 
and (v) that $\partial n_{H}^{*} / \partial s_{H}=\partial n_{F}^{*} / \partial s_{H}=\partial m / \partial s_{H}=0$, so that marginal welfare (24) reduces to

$$
\frac{d W_{H}}{d s_{H}}=-\frac{1}{2}\left(n_{H}^{*}+m^{*}\right)=-\frac{1}{2} N<0 .
$$

By consequence, government $H$ will never set a subsidy compatible with configurations (iii), (iv) and (v); whereas, by symmetry, government $F$ will never set a subsidy compatible with configurations (iii), (iv') and (v'). Tax competition equilibria therefore necessarily occur only in configurations (i) and (ii) (including their borders), which we now analyze in more detail.

(i) Pure single-plant configurations: Suppose that the industry consists of only single-plant firms, as in configuration (i) above. Straightforward calculation shows that changes in prices and locations are given by

$$
\frac{\partial p_{H H}}{\partial n_{F}}=\frac{\partial p_{F F}}{\partial n_{H}}=\frac{c \tau}{2(2 b+c N)} \quad \text { and } \quad \frac{\partial n_{H}^{*}}{\partial s_{H}}=-\frac{\partial n_{F}^{*}}{\partial s_{H}}=\frac{1}{2 K} .
$$

The marginal welfare (24) can hence be rewritten as follows:

$$
\begin{aligned}
\frac{d W_{H}}{d s_{H}} & =-\frac{1}{2} n_{H}-\frac{\partial n_{H}}{\partial s_{H}} s_{H}+\frac{\partial n_{H}}{\partial s_{H}} \frac{L}{2}\left(\frac{\partial S_{H}}{\partial n_{H}}-\frac{\partial S_{H}}{\partial n_{F}}\right) \\
& +\frac{1}{2} \frac{\partial p_{H H}}{\partial n_{F}} \frac{\partial n_{F}}{\partial s_{H}}\left[L \frac{\partial S_{H}}{\partial p_{H H}}+n_{H} \frac{\partial \Pi_{H}^{s}}{\partial p_{H H}}+n_{F} \frac{\partial \Pi_{F}^{s}}{\partial p_{H H}}\right] \\
& +\frac{1}{2} \frac{\partial p_{F F}}{\partial n_{H}} \frac{\partial n_{H}}{\partial s_{H}}\left(n_{H} \frac{\partial \Pi_{H}^{s}}{\partial p_{F F}}+n_{F} \frac{\partial \Pi_{F}^{s}}{\partial p_{F F}}\right) .
\end{aligned}
$$

The first term in (26) stands for the cost of the subsidy paid to all firms located in country $H$. Indeed, when government $H$ increases its subsidy $s_{H}$ it pays an additional amount to all firms established in $H$, with one-half of this subsidy being recouped by local shareholders through profit redistribution. The second term captures the cost of the subsidy due to firms relocating to country $H$ or opening a second production plant there. Since profits across countries are equal in equilibrium, shareholders are unaffected by such a relocation and the cost of the subsidy is simply equal to $s_{H}$. The third term captures the impact of firms' relocation on local consumer surplus. An increase in the subsidy $s_{H}$ attracts plants to country $H$, so that more varieties are produced and sold locally at the price $p_{H H}$ which allows consumers to save on transport costs. The fourth term is identically equal to zero. This is because when profits are evenly redistributed across countries in the model 
by Ottaviano et al. (2002), an increase in $p_{H H}$ reduces the consumer surplus of home residents and augments their share in total profits in exactly the same proportions. The last term finally captures the effect of a change in foreign prices due to the subsidy. An increase in $s_{H}$ entices firms to leave country $F$, which increases prices and profits there and thus benefits to local shareholders. To sum up, the government balances the costs of the subsidy and its associated profit effects with the benefits in local consumer surplus and foreign profits.

In Appendix 1, we show that $d W_{H} / d s_{H}$ is a decreasing function of $s_{H}$ and that $d W_{H} / d s_{H}=0$ if and only if

$$
\begin{aligned}
s_{H}=\widehat{s}_{H}\left(s_{F}\right)= & \frac{8 b+3 c N}{16 b+7 c N} s_{F} \\
& +\frac{1}{2} \tau L(c N+b) \frac{4 a(b+c N)-\tau\left(2 b^{2}+4 b c N+c^{2} N^{2}\right)}{(2 b+c N)(16 b+7 c N)},
\end{aligned}
$$

which is an affine function of $s_{F}$, with positive intercept and a slope less than 1 . When government $F$ increases it subsidy $s_{F}$, government $H$ responds by raising its subsidy $s_{H}$ but by less than the full amount. Hence, in a pure single-plant configuration, subsidies are strategic complements, which is the standard result of the literature. Note that $\widehat{s}_{H}$ shifts upwards when the demand for the differentiated good (i.e., $a$ or $L$ ) increases. This is because in such a case there is a larger volume of imports so that government $H$ has stronger incentives to attract firms in order to save on transport costs incurred by its residents.

Note that when the demand is sufficiently large, on the one hand, $\widehat{s}_{H}$ may lie wholly above the domain of configuration (i). An increase in $s_{H}$ then raises local welfare $\left(d W_{H} / d s_{H}>0\right)$ because the cost of the subsidy is always less than the savings in transport costs. In this case, the optimal subsidy $s_{H}$ lies on the upper border of the domain of configuration (i). When the demand is smaller, on the other hand, $\widehat{s}_{H}$ intersects the domain of configuration (i) for a particular range of subsidies $s_{F}$. If $s_{F}$ belongs to this range, the optimal subsidy is of course given by $\widehat{s}_{H}\left(s_{F}\right)$. If $s_{F}$ lies below any value in this particular interval, then configuration (iv) applies. Since, as argued above, such a value of $\widehat{s}_{H}$ cannot be an optimal subsidy, government $H$ will reduce its subsidy until it reaches the border (16) between configurations (i) and (iv), which then yields the optimal subsidy choice. Finally, if $s_{F}$ lies above any value of this particular interval, the optimal subsidy lies either on the border (15) or on the border (17). This case is illustrated by Figure 2 (borders 
are denoted by their equation numbers). To sum up, in configuration (i) government $H$ 's optimal subsidy is given by a combination of the function $\widehat{s}_{H}\left(s_{F}\right)$ and the borders (15), (16) and (17) (see Figure 2).

Insert Figure 2 about here.

(ii) Mixed configurations: Suppose that the industry comprises all types of firms as is the case in the mixed configuration (ii). Expression (18) shows that changes in location are given by

$$
\frac{\partial n_{H}^{*}}{\partial s_{H}}=0 \quad \text { and } \quad \frac{\partial n_{F}^{*}}{\partial s_{H}}=-\frac{\partial m^{*}}{\partial s_{H}}=-4 \frac{(2 b+c N)}{L(b+c N) \tau^{2} c}<0 .
$$

Hence, an increase in country $H$ 's subsidy has as sole effect to entice singleplant firms in country $F$ to become multi-plant. Stated differently, the subsidy does not alter the number of plants and, therefore, the competition in country F. Still, in contrast to Ottaviano and van Ypersele (2005), the subsidy affects the number of varieties produced locally in the subsidizing country, since it attracts plants. In other words, tax competition is not a 'zero-sum game' in terms of locally produced varieties. ${ }^{11}$

The marginal welfare of the subsidy (24) can be expressed as follows:

$$
\begin{aligned}
\frac{d W_{H}}{d s_{H}} & =-\frac{1}{2}\left(n_{H}+m\right)+s_{H} \frac{\partial n_{F}}{\partial s_{H}}-\frac{1}{2} \frac{\partial n_{F}}{\partial s_{H}}\left(L \frac{\partial S_{H}}{\partial m}-L \frac{\partial S_{H}}{\partial n_{F}}\right) \\
& +\frac{1}{2} \frac{\partial p_{H H}}{\partial n_{F}} \frac{\partial n_{F}}{\partial s_{H}}\left(L \frac{\partial S_{H}}{\partial p_{H H}}+n_{H} \frac{\partial \Pi_{H}^{s}}{\partial p_{H H}}+n_{F} \frac{\partial \Pi_{F}^{s}}{\partial p_{H H}}+m \frac{\partial \Pi^{m}}{\partial p_{H H}}\right)
\end{aligned}
$$

As in a pure single-plant configuration, the first term of (28) stands for the cost of the subsidy paid to all firms located in country $H$ when one-half of the subsidy is recouped by local shareholders. The second term captures again the cost of the subsidy paid to firms opening a plant in country $H$. The third term captures the impact of firms' relocation on local consumer surplus. An increase in $s_{H}$ entices single-plant firms located in $F$ to become multi-plant, which intensifies competition in $H$, thus decreasing local prices and raising consumer surplus. Finally, the fourth term is identically equal to zero, as in the pure single-plant case and for the same reasons.

\footnotetext{
${ }^{11}$ This effect seems to be supported empirically. Indeed, Devereux and Freeman (1995) have reported that tax policy hardly affects the investor's choice between domestic and foreign investment. Even when tax policy affects this choice, it often does not take the form of a simple relocation but consists in the opening of an additional production unit.
} 
It is of interest to note that in a mixed configuration the local consumer surplus $S_{H}$ is independent of $s_{F}$ (and vice-versa for $S_{F}$ ). Indeed, for any given prices, $S_{H}$ can be expressed as a function of $p_{H H}, n_{H}+m$ and $n_{F}$ only. Since $p_{H H}$ depends itself only on $n_{F}$, and since $n_{H}+m=N-n_{F}$ depends also only on $n_{F}$, the surplus $S_{H}$ is independent of $n_{H}$. Since $n_{F}$ does not depend on $s_{F}$, the consumer surplus does not either.

In Appendix 1, we show that $d W_{H} / d s_{H}$ is a decreasing function of $s_{H}$ and that $d W_{H} / d s_{H}=0$ in a mixed configuration if and only if

$$
s_{H}=\widetilde{s}=\frac{3}{4} \phi r-\frac{1}{32} L \tau \frac{b+c N}{2 b+c N}(4 a-2 \tau b+\tau c N) .
$$

Therefore, the subsidy that maximizes local welfare in country $H$ is independent of the other country's subsidy $s_{F}$. This shows that the subsidies are strategically independent whenever a mixed configuration obtains. Each government disregards the action of its rival when it sets its own subsidy. In other words, in the presence of multi-plant firms, tax competition may entirely disappear.

It is furthermore of interest to note that, as is the case of $\widehat{s}_{H}$ discussed before, the subsidy $\widetilde{s}$ shifts upwards when the demand for the differentiated good increases (i.e., $a$ or $L$ increases). The intuition is the same as previously. When demand is large, $\widetilde{s}$ may also lie above the domain of configuration (ii). In that case, an increase in $s_{H}$ always raises local welfare $\left(d W_{H} / d s_{H}>0\right)$, so that the optimal subsidy $s_{H}$ lies on the upper border (20) of the domain of this configuration, i.e., $s_{H}=B$. The optimal subsidy is again independent of $s_{F}$ and there is no subsidy competition. When the demand is small, $\widetilde{s}$ intersects the domain of configuration (ii) for all subsidies $2 B-N K-\widetilde{s} \leq s_{F} \leq B$. When $s_{F}$ belongs to this interval, the optimal subsidy $s_{H}$ is of course given by $\widetilde{s}$. However, when $s_{F}<2 B-N K-\widetilde{s}$, marginal local welfare is negative for every subsidy supported by configuration (ii). The intuition underlying this result is that when $s_{F}$ is small enough, many single-plant firms settle in country $H$ whereas the number of multi-plant firms is small. Still, when there simultaneously exist single- and multi-plant firms, a larger subsidy $s_{H}$ affects only the number of multi-plant firms while it is paid to all firms in the country. As a result, the government prefers to reduce its spending on subsidies up to the point where no multi-plant firms survive. In Figure 2, one can see that government $H$ decreases $s_{H}$ below the smallest admissible value in configuration (ii), i.e., the border (21) which coincides with the border (15) of configuration (i). 
In the previous paragraphs, we have described the optimal subsidy for each given configuration relevant for governments. Yet, each government may set subsidies that induce different configurations, so that its best response to the other country's subsidy may imply changes of firms' production structures. Put differently, governments' best responses will consist of pieces of the optimal subsidies derived above and will include transitions between configurations which may be continuous or discontinuous, depending on parameter values. As shown below, discontinuous transitions are upward jumps in this model, which may give rise to multiple equilibria in the subsidy game.

\subsection{Subsidy equilibria}

We now characterize the equilibrium configurations when governments simultaneously and non-cooperatively set their subsidies. Note from the outset that the existence of pure-strategy Nash equilibria in this subsidy game is guaranteed, because subsidies are defined over a compact subset of $\mathbb{R}$ and because governments' subsidy reaction functions are upward sloping (with a possible upward jump; see Vives, 1999, p.41). We first present the possible equilibrium configurations and then discuss the conditions under which they occur. As suggested by the analysis of optimal subsidies, subsidy equilibria may yield a configuration with only single-plant firms, a mixed configuration including both organizational strutures, or a configuration with only multi-plant firms. We start by describing the former.

(i) A pure single-plant equilibrium exhibits the traditional features of tax competition. When the tax base is internationally mobile, subsidies are strategic complements since each government raises its subsidy in reaction to an increase in the other country's subsidy, to counteract the relocation of mobile firms. Such 'subsidy competition' may lead to an excessive inflation of subsidies or, equivalently, excessively low taxes. Formally, the equilibrium subsidies are such that $s_{H}^{*}=\widehat{s}_{H}\left(s_{F}^{*}\right)$ and $s_{H}^{*}=\widehat{s}_{F}\left(s_{H}^{*}\right)$, which yields

$$
s_{H}^{*}=s_{F}^{*}=\tau L(c N+b) \frac{4 a(c N+b)-\left(2 b^{2}+4 b c N+c^{2} N^{2}\right) \tau}{8(2 b+c N)^{2}}>0 .
$$

First, as can be seen from expression (30), equilibrium subsidies increase with demand ( $a$ and $L$ ). When demand is large, both governments have incentives to attract firms in order for local consumers to save on transport

costs. Second, the equilibrium subsidies are always positive. Indeed, as usual 
in the tax competition literature, governments impose a negative externality on each other and offer too large subsidies or set too low tax rates. Finally, subsidies are independent of firms' fixed costs $\phi$. This is because in a pure single-plant configuration, firms have to pay the whole amount of fixed costs in either country anyway, so that governments may neglect this aspect when deciding on their optimal subsidies.

(ii) A mixed equilibrium is characterized by the following equilibrium subsidies:

$$
s_{H}^{*}=s_{F}^{*}=\widetilde{s},
$$

where $\widetilde{s}$ is given by (29). This illustrates the impact on tax competition of firms being able to endogenously choose their production structure. When single- and multi-plant firms co-exist, governments' subsidy choices are independent. ${ }^{* *}$ Contrary to the pure single-plant case, the equilibrium subsidies now decrease with larger demand (i.e., $a$ and $L$ ), whereas they increase with respect to the cost of a plant. The latter effect is due to the fact that firms now may choose not the pay the cost of the second plant when it is too high; whereas the former effect stems from the fact that increasing demands raise operating profits of multi-plant firms (and therefore, in equilibrium, of all firms), which allows governments to subsidize less (resp., to tax more) without triggering a structural change in firms' organization.**

(iii) A pure multi-plant equilibrium of the subsidy game corresponds to the case on the border between configurations (ii) and (iii), where only multiplant firms operate in the economy. Note that this case naturally occurs for small fixed costs $\phi r$ of a plant. On the one hand, when the economy consists of multi-plant firms only, as in configuration (iii), these firms constitute an immobile tax base which governments tend to tax as much as possible without triggering organizational changes. Hence, the subsidy equilibrium must lie at the point at which any further decrease in subsidies would entice some multiplant firms to modify their structure. On the other hand, a lower subsidy leading to configuration (ii) cannot improve local welfare as its costs for local consumers are higher than its benefits. Therefore, subsidy competition yields an equilibrium where all firms own two plants but some of them are almost willing to shut one down. In such a situation, governments set equilibrium subsidies equal to

$$
s_{H}^{*}=s_{F}^{*}=B=\phi r-\frac{(b+c N)[4 a-(2 b+c N) \tau]}{8(2 b+c N)} L \tau .
$$


As can be seen from expression (32), these are decreasing in demands ( $a$ and $L$ ) and in transport costs $(\tau)$, for the same reasons as in case (ii). Note, finally, that the equilibrium subsidies increase one-to-one with respect to $\phi r$. This is because any increase in $\phi r$ decreases multi-plant firms' profits by exactly that amount, which must be offset by an increase in subsidies for firms to remain multi-plant in equilibrium.

After the description of the possible equilibria, it is of importance to discuss the precise conditions under which they actually occur. As will become clear, there exist sets of parameter values for which multiple equilibria are possible. It turns out to be convenient to discuss the different types of equilibria as a function of the fixed cost $\phi r$ of a plant. When this cost varies, the subsidy equilibria can include single-plant firms only (i), multi-plant firms only (iii), or a mix of both types of firms (ii). In Appendix 2, we define five thresholds $T_{i}$ (for $i=1,2, \ldots 5$ ), which are all positive under the trade feasibility condition and which satisfy $T_{1}<T_{2}, T_{3}<T_{4}<T_{2}$ and $T_{5}<T_{2}$.

First, it is easy to establish the following necessary and sufficient conditions for subsidy equilibria with multi-plant firms only.

Proposition 2 (pure multi-plant equilibrium) The subsidy game yields a pure multi-plant equilibrium (i.e., on the border between configurations (ii) and (iii)) if and only if $\phi r \leq T_{1}$.

Proof. See Appendix 2.

As expected, a pure multi-plant equilibrium of the tax game occurs when the fixed cost of a plant $\phi r$ is small, when product demand ( $a$ or $L$ ) and transport cost $\tau$ are large. When those conditions are not fulfilled, the equilibrium includes at least some single-plant firms.

Necessary and sufficient conditions for the two other configurations (i) and (ii) are hard to come by, because of the discontinuity in the best responses. Yet, we can easily derive necessary conditions for equilibria to arise in the pure single-plant case and in the mixed case.

Proposition 3 (necessary conditions) In the subsidy game,

- if a pure single-plant equilibrium exists (configuration (i)), then $\phi r \geq T_{3}$;

- if a mixed equilibrium exists (configuration (ii)), then $T_{1}<\phi r<T_{2}$.

Proof. See Appendix 2. 
The next proposition establishes sufficient conditions for the different types of equilibria to arise. It furthermore shows that all configurations can be sustained as equilibria for some parameter values, and that there exists a range of parameter values where multiple equilibria arise.

\section{Proposition 4 (sufficient conditions) The subsidy game yields}

- a pure single-plant equilibrium if $\phi r>T_{4}$,

- a mixed equilibrium if $T_{1}<\phi r<T_{5}$.

Proof. See Appendix 2.

Note, finally, that necessary and sufficient conditions can be obtained by combining propositions 3 and 4. Since the conditions in Proposition 4 are not mutually exclusive, different equilibria can exist for the same set of parameter values. Collecting the previous results, we have the following corollary.

\section{Corollary 5 (multiple equilibria) In the subsidy game,}

- there exist simultaneously a pure single-plant and a mixed equilibrium if $\max \left\{T_{1}, T_{4}\right\}<\phi r<T_{5}$,

- there exist simultaneously a pure single-plant and a pure multi-plant equilibrium if $\phi r<\min \left\{T_{1}, T_{4}\right\}$.

The conditions in Corollary 5 illustrate the interesting situation in which there are multiple equilibria in the subsidy game. Indeed, both a pure singleplant equilibrium with low subsidies, and a mixed (resp., a pure multi-plant) equilibrium with high subsidies can be sustained. An illustration of this case is depicted in Figure 2, where the bold solid lines are the optimal subsidies for country $H .{ }^{12}$ As can be seen, the best response has an 'upwards jump', which leads in this case to the existence of a high subsidy equilibrium characterized by the existence of few single-plant and many multi-plant firms; and a low subsidy equilibrium characterized by the existence of only single-plant firms.

\footnotetext{
${ }^{12}$ The parameter values underlying Figure 2 are as follows: $\alpha=1, \beta=1, \gamma=0.5$, $N=5, L=10, \tau=0.1, \phi=1$ and $r=0.33$. The red parts of the optimal subsidies are not globally feasible choices, since they correspond to a local maximum only; hence, the government will choose globally optimal subsidies (depicted in black) associated with another production structure for firms.
} 
The economy may get stuck in either one of the two equilibria. In the example depicted in Figure 2, the high subsidy equilibrium yields higher welfare than the low subsidy equilibrium. This is because more multi-plant firms decrease prices and costly transportation in the economy, whereas the subsidy is not too costly since it comes partly back to the shareholders via firms' profits. Yet, we argue in the next section that the high subsidy equilibrium may actually be worse than the low subsidy equilibrium when a share of profits goes to the rest of the world. In that case, subsidy competition leads to excessively high subsidies, which are costly since they feed back into profits that accrue to shareholders in the rest of the world. This suggests that small open countries may be less able to profitably subsidize firms to attract investment, because subsidies are more costly for them ('subsidy trap').

We conclude this section by a remark on the level of subsidies. In configuration (i) with only single-plant firms, subsidies are always positive and independent of the cost of capital. However, in configuration (ii) including multinationals, subsidies may be positive or negative depending on the cost of a plant. Capital may be taxed in the equilibrium of the subsidy game when fixed costs are small or when product demand is large. Stated differently, multinational firms represent an immobile tax base which governments may profitably tax.

\section{Discussion}

We now discuss some extensions of our model and analyze the robustness of our main findings.

\subsection{Market integration and trade barriers}

How does international market integration affect the nature of the tax equilibrium and the values of the subsidies? In Krugman (1991), market integration is presented as a reduction of trade barriers or, equivalently, an increases in the freeness of trade. In this section we show that a fall in trade barriers may intensify or attenuate subsidy competition.

First, from (15)-(17) it can be seen that decreasing trade barriers make the boundary (15) shift outwards, whereas the two boundaries (16) and (17) shift inwards. Hence, pure-single plant equilibria are more likely to arise for small trade barriers. Note that when $\tau$ is close to 0 , the equilibrium involves 
only single-plant firms and subsidy competition vanishes $\left(s_{H}^{*}=s_{F}^{*}=0\right)$. This is because when trade is costless, consumers in both countries have the same access to all varieties independently of their place of production, so that it is pointless to attract firms using subsidies.

It is also readily verified that

$$
\frac{\partial s_{H}^{*}}{\partial \tau} \gtreqless 0 \quad \Longleftrightarrow \quad \tau \lesseqgtr \bar{\tau} \equiv \frac{2 a(b+c N)}{2 b^{2}+4 c N b+c^{2} N^{2}},
$$

where the threshold $\bar{\tau}<\tau_{\text {trade }}$. Hence, when trade costs fall below some threshold, any further decrease will reduce the equilibrium subsidies. This is because the gain of having local firms falls with smaller trade costs, which reduces governments' incentives to offer subsidies to attract firms. Yet, beyond some threshold of trade barriers, demands for imports become small whereas subsidies are still costly. This entices governments to reduce their subsidies when trade barriers get larger. Therefore, equilibrium subsidies will be largest for intermediate values of trade barriers since the gain from having local production is largest there.

Concerning the mixed configuration, one can see from (19)-(21) that decreasing trade barriers make all boundaries shift inwards to the origin, so that the area supporting this configuration shrinks. It is readily verified that

$$
\frac{\partial \widetilde{s}_{H}}{\partial \tau}=-\frac{L(b+c N)(2 a-2 b \tau+c N \tau)}{16(2 b+c N)}<0
$$

where the last inequality holds because of the trade feasibility condition (10). Hence, a fall in trade barriers raises the level of subsidies. The intuition is that smaller trade barriers decrease the returns to being multinational and induces fewer firms to operate a second plant. This in turn leads to governments having larger incentives to subsidize capital, since the tax base becomes more mobile and since residents eventually cash in the dividends of more profitable firms.

Proposition 6 In a pure single-plant equilibrium, a fall in trade barriers relaxes subsidy competition when trade costs are sufficiently low, whereas it intensifies it for large trade barriers. In particular, subsidy competition will be the strongest, and equilibrium subsidies will be highest, for intermediate levels of integration. 


\subsection{Profit distributions}

Until now we have considered that all profits are redistributed to the two countries and that this redistribution is equal across countries. We now assume that a share $0 \leq \lambda_{H}<1$ of profits and capital rents accrue to country $H$ 's agents, whereas a share $0 \leq \lambda_{F}<1$ goes to agents in country $F$, with $\lambda_{H}+\lambda_{F} \leq 1$. We further assume that some share of profits and capital rents may go to absentee shareholders in the rest of the world, i.e. $\lambda_{H}+\lambda_{F}<1$ is possible. Without loss of generality, we consider that country- $H$ residents have a claim to a share $\lambda_{H} \geq \lambda_{F}$, i.e., country $H$ gets a larger share of the redistributed profits. Redefine welfare (23) in country $H$ as follows,

$$
\begin{aligned}
W_{H}= & \frac{L S_{H}}{2}+\lambda_{H}\left[n_{H}\left(\Pi_{H}^{s}+\phi r+s_{H}\right)+n_{F}\left(\Pi_{F}^{s}+\phi r+s_{F}\right)\right. \\
& \left.+m\left(\Pi^{m}+2 \phi r+s_{H}+s_{F}\right)\right]-\left(n_{H}+m\right) s_{H} .
\end{aligned}
$$

Some lines of computations show that the pure single-plant optimal subsidy in configuration (i) is given by

$$
\begin{aligned}
\widehat{s}_{H}\left(s_{F}\right)= & \frac{8 b+c N\left(5-4 \lambda_{H}\right)}{16 b+c N\left(9-4 \lambda_{H}\right)} s_{F} \\
& +\frac{L(b+c N) \tau\left(2 a(b+c N)-\left(b^{2}+c N\left(3-2 \lambda_{H}\right) b+c^{2} N^{2}\left(1-\lambda_{H}\right)\right) \tau\right)}{(2 b+c N)\left(16 b+c N\left(9-4 \lambda_{H}\right)\right)},
\end{aligned}
$$

which has still a positive slope less than unity and a positive intercept. A symmetric expression holds for country $F$. The equilibrium of the subsidy competition game is $\left(s_{H}^{*}, s_{F}^{*}\right)$ where $s_{H}^{*}$ is no longer equal to $s_{F}^{*}$. In the case of a mixed configuration (ii), the equilibrium subsidy is given by

$$
\widetilde{s}_{H}=\frac{3 c N+4 b\left(1+\lambda_{H}\right)}{8 b+c N\left(5-2 \lambda_{H}\right)} \phi r-L(b+c N) \tau \frac{2 a-\left(b+c N\left(\lambda_{H}-1\right)\right) \tau}{4\left(8 b+c N\left(5-2 \lambda_{H}\right)\right)}
$$

which is again independent of $s_{F}$. This shows that the strategic independence of subsidies in the mixed congiguration is not an artifact of our equal profit redistribution assumption. We can further show that $\partial s_{H}^{*} / \partial \lambda_{H}>0$ and $\partial \widetilde{s}_{H} / \partial \lambda_{H}>0$, the same conditions applying to country $F$.

Proposition 7 An increase in country $i$ 's share of profits $\lambda_{i}$ raises equilibrium subsidies in both the pure single-plant and the mixed configurations.

Proof. See Appendix 3. 
When all firms are single-plant, subsidies are used to attract firms and increase firms profits after subsidy. Moreover, subsidies are partly recouped by the shareholders residing in the countries that grant the subsidies. Therefore, if absentee shareholders own only a small share of the industry profits (large value of $\lambda_{H}+\lambda_{F}$ ), the cost of subsidizing capital is small and each government tends to subsidize more.

It is of interest to compare the difference in equilibrium subsidies when shares in capital and profits differ across countries. We can show the following result.

Proposition 8 The country with the larger share of claims to profits subsidizes more (or taxes less) in equilibrium. Furthermore, the subsidy gap $s_{H}^{*}-s_{F}^{*}$ is always increasing with trade costs, whereas the subsidy gap $\widetilde{s}_{H}-\widetilde{s}_{F}$ is decreasing when $\tau<2 a /(10 b+3 c N)<\tau_{\text {trade }}$ and increasing otherwise.

Proof. See Appendix 3.

The intuition underlying Proposition 8 is that part of the subsidy is recouped through firms' profits, which makes the subsidy less costly for the country having higher profit claims and, therefore, leads to an increase in it. Furthermore, in the single-plant case international integration reduces the tax gap between countries. This is because, contrary to Baldwin and Krugman (2004), there are no agglomeration economies that can be taxed away in our model and because not all firms are agglomerated in one country. Yet, in the presence of multinational firms, the tax base becomes partly immobile, so that for some range of parameter values a deepening international integration may actually raise the equilibrium subsidies.

To conclude this section, the important thing to note is that the general shape of governments' best responses does not depend on how profits are shared within the two countries and between the two countries and the rest of the world. Of course, the equilibria become asymmetric and take different values when $\lambda_{H} \neq \lambda_{F}$, yet the general nature of the regimes remains the same. This suggests that our findings are robust.

\section{Conclusions}

We have developed a model of subsidy competition with multinational firms and we have shown that when firms are able to choose their location and 
organizational structure, the impact of subsidies on prices and profits differ. In particular, when the cost of a second plant is large relative to the costs or exporting goods, firms prefer to operate a single plant. When the subsidy in a country rises, firms relocate their plant to that country, which increases competition there and relaxes it in the other country. Profits before subsidy increase in the latter locale, whereas they decrease before subsidy, but increase after subsidy, in the former one. On the contrary, when the cost of a second plant is small relative to the costs of exporting goods, some firms prefer to operate a plant in every country. In that case, when the subsidy in a country rises some single-plant firms choose to open a second plant in this country. This increases competition there without relaxing it in the other country. Competition increases globally in the economy, which reduces prices and profits before subsidies. Yet, in contrast to the case with single-plant firms, the additional subsidy does not offset the fall in profits so that profits after subsidy actually decrease. Thus, subsidies may trigger a rise or a fall in profits, depending on firms' changes in operational structure in response to the subsidy.

The different impacts of subsidies on firms' locational and organizational choices affect governments' equilibrium subsidies. In the absence of multinationals, firms locate according to subsidy differences and competition for mobile capital entices governments to inflate subsidies. This is the traditional result of the tax competition literature. However, higher subsidies reduce the cost of capital and may hence affect firms' organization as the latter may choose to set up several plants. When many firms run plants in all countries, a reduction in a country's subsidy induces some firms to shut down the plant located in that country whereas the government in that country is able to save subsidies on all multinational firms that keep their plants there. This may explain why competition for mobile capital is less fierce once a sufficient mass of multinationals operate in the global economy, and why the prediction of 'race to the bottom' lacks empirical support.

\section{References}

[1] Baldwin, R.E. and P.R. Krugman (2004) Agglomeration, integration and tax harmonization, European Economic Review 48, 1-23. 
[2] Barba Navaretti, G.B. and A.J. Venables (2004) Multinational firms in the world economy. Princeton, NJ: Princeton Univ. Press.

[3] Borck, R. and M. Pflüger (2005) Agglomeration and tax competition. Forthcoming in European Economic Review.

[4] Cummins, J., and R.G. Hubbard (1995) The Tax Sensitivity of Foreign Direct Investment: Evidence from Firm-Level Panel Data. In Feldstein M., J.R. Hines, and R.G. Hubbard (eds): Effects of Taxation on Multinational Corporations. Chicago: Univ. of Chicago Press.

[5] Devereux, M.P. and H. Freeman (1995) The impact of tax on foreign direct investment: empirical evidence and the implications for tax integration schemes, International Tax and Public Finance 2, 85-106.

[6] Devereux, M., R. Griffith and A. Klemm (2002) Corporate income tax reforms and international tax competition, Economic Policy 35, 451495.

[7] Devereux, M.P. and G. Hubbard (2003) Taxing multinationals, International Taxation and Public Finance 10, 469-487.

[8] Fujita, M., P. Krugman and A.J. Venables (1999) The Spatial Economy. Cities, Countries and International Trade. Cambridge, MA: MIT Press.

[9] Fujita, M. and J.-F. Thisse (2002) Economics of Agglomeration: Cities, Industrial Location and Regional Growth. Cambridge: Cambridge Univ. Press.

[10] Görg, H. and D.E. Greenaway (2002) Much ado about nothing? Do domestic firms really benefit from foreign investment? CEPR Discussion Paper $n^{\circ} 3485$, London.

[11] Haskel, J. and H. Wolf (2001) The law of one price - A case study, Scandinavian Journal of Economics 103, 545-558.

[12] Haufler, A. and I. Wooton (1999) Country size and tax competition for foreign direct investment, Journal of Public Economics 71, 121-139.

[13] Haufler, A. and I. Wooton (2005) The effects of regional tax and subsidy coordination on foreign direct investment. Forthcoming in European Economic Review. 
[14] Head, K. and T. Mayer (2000) Non-Europe. The magnitude and causes of market fragmentation in the EU, Weltwirtschaftliches Archiv 136, 284-314.

[15] Helpman, E. and P. Krugman (1985) Market Structure and Foreign Trade. Cambridge, MA: MIT Press.

[16] Krugman, P. (1980) Scale economies, product differentiation and the pattern of trade, American Economic Review 70, 950-959.

[17] Krugman, P. (1991) Increasing returns and economic geography, Journal of Political Economy 99, 483-499.

[18] Ludema, R. and I. Wooton (2000) Economic geography and the fiscal effects of regional integration, Journal of International Economics 52, 331-357.

[19] Markusen, J.R. and A.J. Venables (1998) Multinational firms and the new trade theory, Journal of International Economics 46, 183-203.

[20] Markusen, J.R. and A.J. Venables (2000) The theory of endowment, intra-industry and multi-national trade, Journal of International Economics 52, 209-234.

[21] Oates, W. (1972) Fiscal Federalism. Orlando, FL: Harcourt Brace Jovanovich.

[22] Ottaviano G.I.P., T. Tabuchi and J.-F. Thisse (2002) Agglomeration and trade revisited, International Economic Review 43, 409-436.

[23] Ottaviano, G.I.P. and J.-F. Thisse (2004) Agglomeration and economic geography. In: Henderson, J.V. and J.-F. Thisse (eds.). Handbook of Regional and Urban Economics, Volume IV (Amsterdam, North-Holland), pp. 2563-2608.

[24] Ottaviano, G.I.P. and T. van Ypersele (2005) Market size and tax competition. Forthcoming in Journal of International Economics.

[25] Raff, H. (2004) Preferential trade agreements and tax competition for foreign direct investment, Journal of Public Economics 88, 2745-2763. 
[26] UNCTAD (2000) Tax incentives and foreign direct investment: a global survey. Geneva and New York: United Nations Publication.

[27] Vives, X. (1999) Oligopoly Pricing: Old Ideas and New Tools. Cambridge, MA: MIT Press.

[28] Wildasin, D. (1988) Nash equilibria in models of fiscal competition, Journal of Public Economics 32, 229-40.

[29] Wilson, J.D. (1986) A theory of interregional tax competition, Journal of Urban Economics 19, 296-315.

[30] Wilson, J.D. (1999) Theories of tax competition, National Tax Journal $52,269-304$.

\section{Appendix 1: Optimal subsidies}

In this appendix, we derive the optimal subsidies for configurations (i) and (ii). First, we compute

$$
\begin{aligned}
\frac{\partial S_{H}}{\partial n_{H}}= & -\frac{1}{2} p_{H H}\left[2 a-(b+c N) p_{H H} b+2 p_{H H} c\left(n_{H}+n_{F}\right)+c n_{F} \tau\right] \\
\frac{\partial S_{H}}{\partial n_{F}}= & -\frac{1}{8}\left(\tau+2 p_{H H}\right)\left[-2(b+c N) p_{H H} b+4 p_{H H} c\left(n_{F}+n_{H}\right)\right. \\
& \left.-c N \tau-b \tau+4 a+2 c n_{F} \tau\right]
\end{aligned}
$$

which we will use in both cases.

Optimal subsidies in configuration (i): In the pure single-plant case, some straightforward calculations show that

$$
\begin{gathered}
n_{H} \frac{\partial \prod_{H}^{s}}{\partial p_{H H}}=n_{H}(b+c N) L p_{H H}, \quad n_{F} \frac{\partial \prod_{F}^{s}}{\partial p_{H H}}=\frac{1}{2} n_{F} L(b+c N)\left(2 p_{H H}-\tau\right) \\
n_{H} \frac{\partial \prod_{H}^{s}}{\partial p_{F F}}=\frac{1}{2} n_{H} L(b+c N)\left(2 p_{F F}-\tau\right) \quad n_{F} \frac{\partial \prod_{F}^{s}}{\partial p_{F F}}=n_{F}(b+c N) L p_{F F}
\end{gathered}
$$

and

$$
\frac{\partial S_{H}}{\partial p_{H H}}=-a N+b p_{H H} N+\frac{1}{2} n_{F} \tau b .
$$


Using these intermediate results, as well as the equilibrium prices (8) and the equilibrium distribution of firms (14), we can compute the following expressions:

$$
\begin{aligned}
-\frac{1}{2} n_{H}-\frac{\partial n_{H}}{\partial s_{H}} s_{H} & =-\frac{1}{4 K}\left(N K+3 s_{H}-s_{F}\right) \\
\frac{\partial S_{H}}{\partial n_{H}}-\frac{\partial S_{H}}{\partial n_{F}} & =\frac{\tau(2 a-\tau b)}{4} \frac{b+c N}{2 b+c N}-\frac{s_{H}-s_{F}}{2 L} \\
L \frac{\partial S_{H}}{\partial p_{H H}}+n_{H} \frac{\partial \prod_{H}^{s}}{\partial p_{H H}}+n_{F} \frac{\partial \prod_{F}^{s}}{\partial p_{H H}} & =(2 b+c N) L N\left[p_{H H}-\frac{2 a+c n_{F} \tau}{2(2 b+c N)]=0}\right. \\
\frac{1}{2} n_{H} \frac{\partial \prod_{H}^{s}}{\partial p_{F F}}+\frac{1}{2} n_{F} \frac{\partial \prod_{F}^{s}}{\partial p_{F F}} & =\frac{n_{H} L(b+c N)\left(2 p_{F F}-\tau\right)}{4}+\frac{n_{F}(b+c N) L p_{F F}}{2} \\
& -\frac{\left(s_{H}-s_{F}\right) b}{c \tau}+\frac{N L(2 a-b \tau)}{4} \frac{b+c N}{2 b+c N}
\end{aligned}
$$

Substituting these expressions into the marginal welfare (26) it is readily verified that $d W_{H} / d s_{H} \geq 0$ if and only if

$$
\begin{aligned}
& -2(2 b+c N)(16 b+7 c N) s_{H}+2(8 b+3 c N)(2 b+c N) s_{F} \\
& \quad+\tau L(b+c N)\left(4 a(b+c N)-\tau\left(2 b^{2}+4 b c N+N^{2} c^{2}\right)\right) \geq 0,
\end{aligned}
$$

which shows that local welfare $W_{H}$ is concave in $s_{H}$ and that the optimal subsidy is given by $\widehat{s}_{H}\left(s_{F}\right)$.

Optimal subsidies in configuration (ii): In the mixed configurations, we readily obtain

$$
L \frac{\partial S_{H}}{\partial p_{H H}}=\frac{L b \tau}{2} n_{F}-L N\left(a-b p_{H H}\right), \quad n_{H} \frac{\partial \prod_{H}^{s}}{\partial p_{H H}}=n_{H}(b+c N) L p_{H H}
$$

and

$$
n_{F} \frac{\partial \prod_{F}^{s}}{\partial p_{H H}}=\frac{L(b+c N)}{2} n_{F}\left(2 p_{H H}-\tau\right), \quad m \frac{\partial \Pi^{m}}{\partial p_{H H}}=m L(b+c N) p_{H H} .
$$

This allows us to compute

$$
\begin{aligned}
\frac{L}{2} \frac{\partial S_{H}}{\partial p_{H H}}+\frac{n_{H}}{2} \frac{\partial \Pi_{H}^{s}}{\partial p_{H H}}+\frac{n_{F}}{2} \frac{\partial \Pi_{F}^{s}}{\partial p_{H H}}+\frac{m}{2} \frac{\partial \Pi^{m}}{\partial p_{H H}} & =(2 b+c N) L N\left[p_{H H}-\frac{2 a+c n_{F} \tau}{2(2 b+c N)}\right] \\
& =0
\end{aligned}
$$




$$
\begin{aligned}
-\frac{1}{2}\left(n_{H}+m\right)+s_{H} \frac{\partial n_{F}}{\partial s_{H}}= & \frac{2(2 b+c N)}{L(b+c N) \tau^{2} c}\left(\phi r-\frac{(b+c N)[4 a-(2 b+c N) \tau]}{8(2 b+c N)} L \tau\right. \\
& \left.-3 s_{H}\right)-\frac{N}{2} \\
L \frac{\partial S_{H}}{\partial m}-L \frac{\partial S_{H}}{\partial n_{F}}= & \frac{L \tau\left(a-b p_{H H}\right)}{2}-\frac{L \tau^{2}\left(b+c N-2 n_{F} c\right)}{8} \\
= & -s_{H}+\phi r
\end{aligned}
$$

Substituting these expressions into the marginal welfare (28), we obtain

$$
\begin{aligned}
\frac{d W_{H}}{d s_{H}}= & -8 s_{H} \frac{2 b+c N}{L(b+c N) \tau^{2} c}-\frac{L(b+c N) \tau(4 a-2 \tau b+c \tau N)-16 \phi r(2 b+c N)}{4 L(b+c N) \tau^{2} c}, \\
& +2 \frac{(2 b+c N)}{L(b+c N) \tau^{2} c} \phi r \\
= & -8 s_{H} \frac{2 b+c N}{L(b+c N) \tau^{2} c}-\frac{L(b+c N) \tau(4 a-2 \tau b+c \tau N)-24 \phi r(2 b+c N)}{4 L(b+c N) \tau^{2} c}
\end{aligned}
$$

which shows that local welfare is concave in $s_{H}$ and that the optimal subsidy is given by (29).

\section{Appendix 2: Subsidy equilibria}

The five thresholds $T_{i}>0$ are defined as follows:

$$
\begin{aligned}
& T_{1} \equiv \frac{L(b+c N) \tau(12 a-(6 b+5 c N) \tau)}{8(2 b+c N)} \\
& T_{2} \equiv \frac{L(b+c N) \tau(12 a-(6 b+N c) \tau)}{8(2 b+c N)} \\
& T_{3} \equiv \frac{L(b+c N) \tau\left[4 a(3 b+2 c N)-\left(6 b^{2}+6 c N b+c^{2} N^{2}\right) \tau\right]}{8(2 b+c N)^{2}} \\
& T_{4} \equiv \frac{L(b+c N)(3 b+2 c N) \tau(2 a-b \tau)}{4(2 b+c N)^{2}} \\
& T_{5} \equiv \frac{1}{8} L(b+c N) \tau \frac{4 a(60 b+31 c N)-\tau\left(120 b^{2}+90 b c N+13 c^{2} N^{2}\right)}{(2 b+c N)(28 b+13 c N)}
\end{aligned}
$$

They will be useful in characterizing the occurence of the different types of equilibria in propositions $2-4$. 


\section{Proof of Proposition 2}

A necessary condition for a configuration with only multi-plant firms is given by $\widetilde{s} \geq B$. Some computations show that this is equivalent to $\phi r \leq$ $T_{1}$. A sufficient condition is that $s_{H}=B$ is government $H$ 's best response to the subsidy $s_{F}=B$. When $s_{F}=B$, government $H$ 's subsidy yields configurations ( $\left.\mathrm{v}^{\prime}\right)$, (ii) and (iii) as $s_{H}$ rises (see Figure 1). However, welfare in country $H$ is always constant in configuration ( $\mathrm{v}^{\prime}$ ) ( since $n_{H}+m=0$, so that there are no firms subsidize in country $H$ ). It is furthermore increasing in $s_{H}$ in configuration (ii) and, by (25), decreasing in configuration (iii). This shows that $\left(s_{H}, s_{F}\right)=(B, B)$ is an equilibrium.

\section{Proof of Proposition 3}

Let us start with the pure single-plant configuration. This type of equilibrium arises only if conditions (15)-(17), when evaluated at (30), hold. Because subsidies are symmetric, this requires that $\widehat{s}_{H}\left(s_{F}^{*}\right) \leq 2 B-N K-s_{F}^{*}$, or more simply that $2 s_{H}^{*} \leq 2 B-N K$, holds. Some straightforward calculations show that this is the case when $T_{3} \leq \phi r$.

Concerning the mixed configurations let $\left(s_{H}^{1}, s_{F}^{1}\right)$ be the intersection points of $s_{H}=\widetilde{s}$ with the line $s_{H}=2 B-N K-s_{F}$. This intersection point is given by

$$
s_{H}^{1}=\widetilde{s} \quad \text { and } \quad s_{F}^{1}=\frac{5}{4} \phi r-\frac{L(b+c N) \tau[28 a-(14 b+c N) \tau]}{32(2 b+c N)}
$$

A necessary condition for the existence of a mixed equilibrium is then given by $s_{F}^{1}<s_{H}^{1}<B$, which yields $T_{1}<\phi r<T_{2}$.

\section{Proof of Proposition 4}

In this appendix, we derive sufficient conditions for single- and multi-plant equilibria to exist.

(i) Single-plant firms only: A sufficient condition with respect to subsidies is given by $s_{H}^{*}<B-N K$, which is equivalent to $\phi r>T_{4}$. Because one can readily show that $T_{4}>T_{3}$, this condition satisfies the necessary condition $\phi r \geq T_{3}$, as presented in Proposition 3 .

(ii) Mixed case: Let $\left(s_{H}^{2}, s_{F}^{2}\right)$ be the intersection points of $\widehat{s}_{H}\left(s_{F}\right)$ with the line $s_{H}=2 B-N K-s_{F}$. One can compute that

$$
s_{F}^{2}=\frac{16 b+7 c N}{12 b+5 c N} \phi r-\frac{L(b+c N) \tau(18 a-9 b \tau-c N \tau)}{4(12 b+5 c N)}
$$


A sufficient condition for a configuration with all types of firm structures is given by $s_{F}^{2}<\widetilde{s}$ and $T_{1}<\phi r<T_{2}$. The first condition is equivalent to

$\phi r<T_{5}=\frac{1}{8} L(b+c N) \tau \frac{4 a(60 b+31 c N)-\tau\left(120 b^{2}+90 b c N+13 c^{2} N^{2}\right)}{(2 b+c N)(28 b+13 c N)}<T_{2}$

Thus, such an equilibrium exist if $T_{1}<\phi r<T_{5}$. This interval is not empty if $\tau$ and $c N / b$ are sufficiently large.

\section{Appendix 3: Discussion}

\section{Proof of Proposition 7}

Some straightforward computions show that

$$
\frac{\partial s_{H}^{*}}{\partial \lambda_{H}}=\frac{c L N(b+c N)\left(12 b+c N\left(7-4 \lambda_{F}\right)\right)\left(16 b+c N\left(9-4 \lambda_{F}\right)\right) \tau^{2}}{8(2 b+c N)\left(12 b+c N\left(-2 \lambda_{F}-2 \lambda_{H}+7\right)\right)^{2}}<0 .
$$

Some further computations show that

$$
\frac{\partial \widetilde{s}_{H}}{\partial \lambda_{H}}>0 \Longleftrightarrow \phi r>\frac{c L N(b+c N) \tau(4 a-10 b \tau-3 c N \tau)}{8\left(16 b^{2}+14 c N b+3 c^{2} N^{2}\right)}
$$

Since the RHS of the above expression lies always below the threshold $T_{1}$, we conclude that $\partial \widetilde{s}_{H} / \partial \lambda_{H}>0$ always hold in the mixed configuration because $T_{1} \leq \phi r \leq T_{2}$ must be satisfied for this configuration to arise.

\section{Proof of Proposition 8}

Some longer computations reveal that, the difference in equilibrium subsidies in the pure single-plant case is equal to

$$
s_{H}^{*}-s_{F}^{*}=\frac{c L N(b+c N) \lambda\left(\lambda_{H}-\lambda_{F}\right) \tau^{2}}{24 b+2 c N\left(7-2\left(\lambda_{H}+\lambda_{F}\right)\right)} \geq 0
$$

since we assume that $\lambda_{H} \geq \lambda_{F}$. Furthermore, in the mixed equilibrium we have

$\widetilde{s}_{H}-\widetilde{s}_{F}=\frac{\left(\lambda_{H}-\lambda_{F}\right)[8(2 b+c N)(8 b+3 c N) r \phi-c L N(b+c N) \tau(4 a-10 b \tau-3 c N \tau)]}{4\left(8 b+c N\left(5-2 \lambda_{F}\right)\right)\left(8 b+c N\left(5-2 \lambda_{H}\right)\right)}$

the sign of which is therefore determined as in (34). 


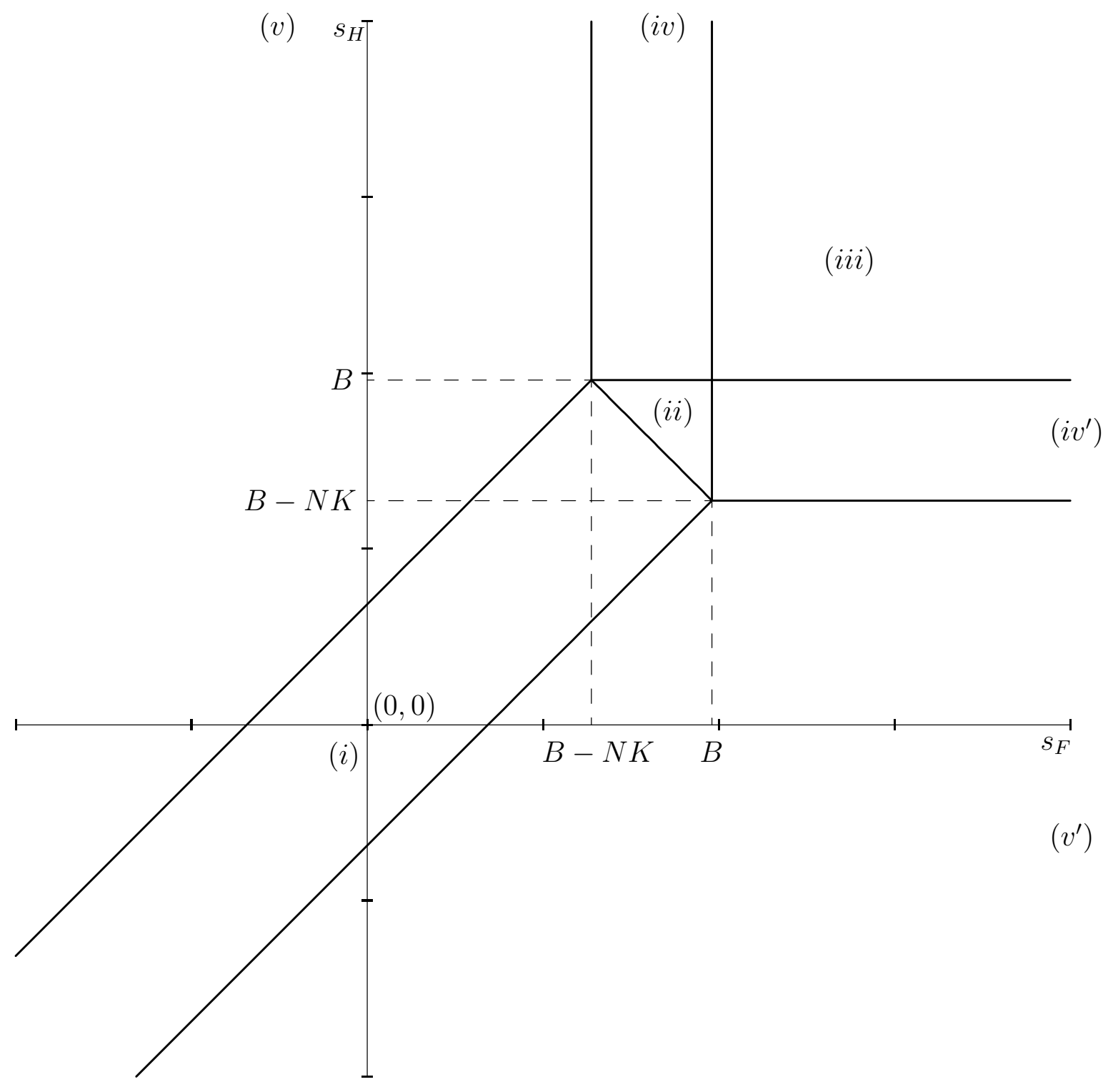

Figure 1: Spatial equilibrium structures 


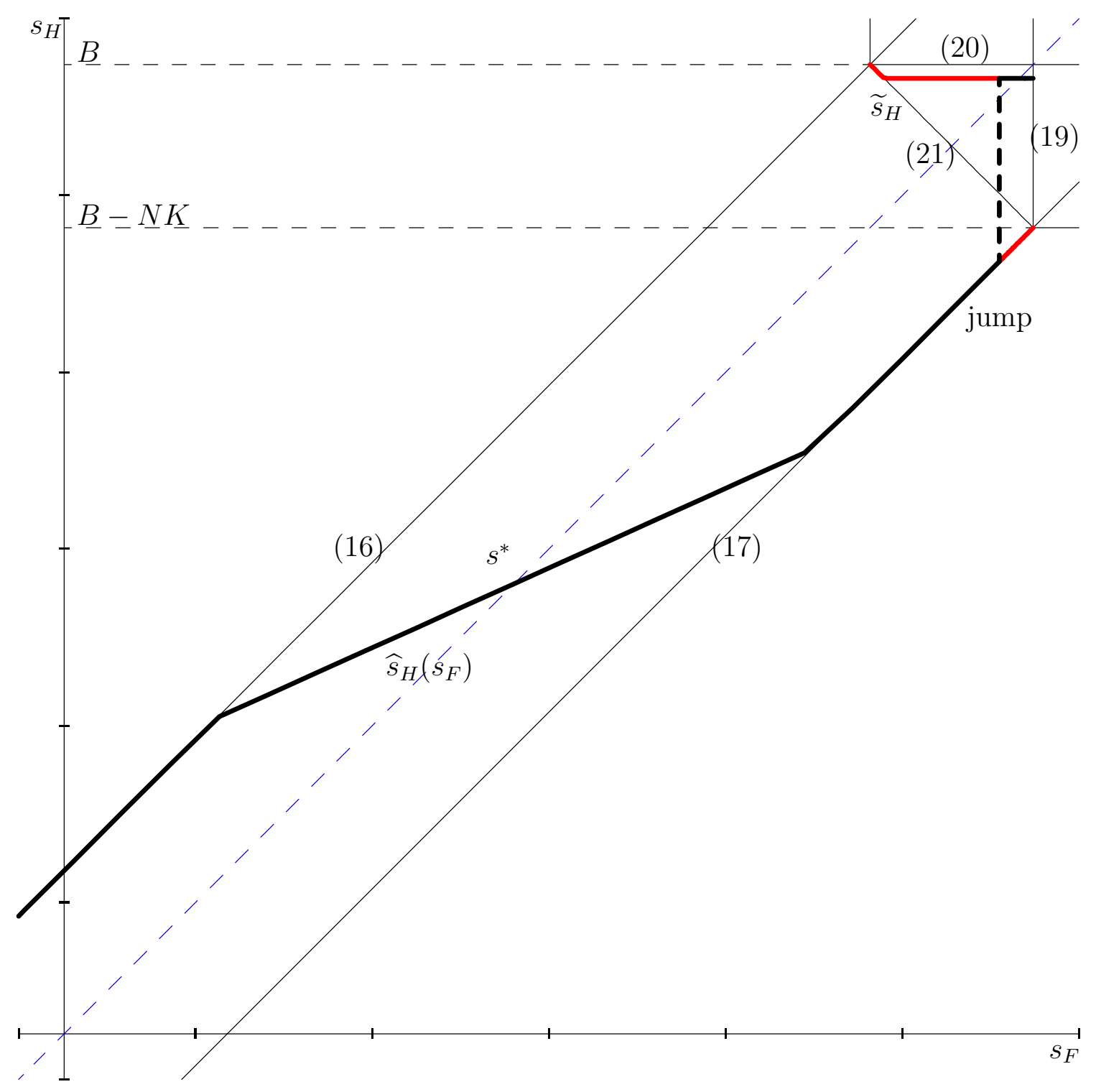

Figure 2: Country H's best response and multiple equilibria 